\title{
Plasma-induced field emission study of carbon nanotube cathode
}

\author{
Yi Shen, ${ }^{*}$ Liansheng Xia, Huang Zhang, Xingguang Liu, Anmin Yang, Jinshui Shi, and Linwen Zhang \\ Institute of Fluid Physics, China Academy of Engineering Physics, \\ P.O. Box 919-106, Mianyang 621900, People's Republic of China \\ Qingliang Liao and Yue Zhang \\ Department of Materials Physics, State Key Laboratory for Advanced Metals and Materials, \\ University of Science and Technology Beijing, Beijing 100083, People's Republic of China
}

(Received 16 July 2011; published 11 October 2011)

\begin{abstract}
An investigation on the plasma-induced field emission (PFE) properties of a large area carbon nanotube (CNT) cathode on a $2 \mathrm{MeV}$ linear induction accelerator injector is presented. Experimental results show that the cathode is able to emit intense electron beams. Intense electron beams of $14.9-127.8 \mathrm{~A} / \mathrm{cm}^{2}$ are obtained from the cathode. The CNT cathode desorbs gases from the CNTs during the PFE process. The fast cathode plasma expansion affects the diode perveance. The amount of outgassing is estimated to be $0.06-0.49 \mathrm{~Pa} \cdot \mathrm{L}$, and the ratio of outgassing and electron are roughly calculated to be within the range of 170-350 atoms per electron. The effect of the outgassing is analyzed, and the outgassing mass spectrum of the CNT cathode has been studied during the PFE. There is a significant desorption of $\mathrm{CO}_{2}, \mathrm{~N}_{2}(\mathrm{CO})$, and $\mathrm{H}_{2}$ gases, which plays an important role during the PFE process. All the experiments demonstrate that the outgassing plays an important role in the formation of the cathode plasma. Moreover, the characteristic turn-on time of the CNT cathode was measured to be 39 ns.
\end{abstract}

DOI: 10.1103/PhysRevSTAB.14.104701

PACS numbers: 29.25.Bx

\section{INTRODUCTION}

Velvet is one of the materials for explosive electron emission (EEE) in intense electron beam sources [1-3]. The velvet cathode generates uniform cathode plasma during the emission process under pulsed high voltage. Intense electron beams are extracted from cathode plasma. The plasma expansion velocity of the velvet cathode is less than $1 \mathrm{~cm} / \mu \mathrm{s}$. However, the velvet cathode has low lifetime and high outgassing during intense electron emission. Thus, the velvet cathode is not the best option for pulsed power applications.

Carbon nanotubes (CNTs) have been widely used due to their nanometer scale, superior mechanical strength, good conductance, and high thermal and chemical stability [4-9]. The CNTs are now being investigated as field emission cathodes for a wide range of applications. Vacuum electron devices including field emission display [10,11], $\mathrm{x}$-ray source $[12,13]$, and electron source [14] have been demonstrated. In the previous field emission studies, especially in the field emission display, CNTs were mainly applied to DC electric fields. The field emission current density only reached $\mu \mathrm{A} / \mathrm{cm}^{2} \sim \mathrm{mA} / \mathrm{cm}^{2}$. Some studies

\footnotetext{
*shenygo@163.com
}

Published by the American Physical Society under the terms of the Creative Commons Attribution 3.0 License. Further distribution of this work must maintain attribution to the author(s) and the published article's title, journal citation, and DOI. were focused on intense current field emission properties of CNTs for application in linear induction accelerators (LIAs) [15-17] and high power microwave tubes [18,19]. The field emission current density can reach hundreds of $\mathrm{A} / \mathrm{cm}^{2}$.

In our study, we have utilized plasma-induced field emission (PFE) that is a little different from the EEE process. During the EEE process [20], the gas from the explosion vaporization of cathode material is ionized to form cathode plasma. But in the PFE process, the neutral gas which is desorbed from the cathode is ionized. In this paper, we have investigated the PFE properties of a large area CNT cathode for single pulse mode on a $2 \mathrm{MeV}$ LIA injector [21], including intense electron emission, outgassing mass spectrum (OMS), and characteristic turn-on time (CTT).

\section{EXPERIMENTAL SETUP}

The CNT cathode was tested on a $2 \mathrm{MeV}$ LIA injector. Figure 1 shows the schematic diagram of the experimental setup for the cathode testing. The pulse power system includes mainly a Marx generator and four Blumlein lines; the system generates $250 \mathrm{kV}, 100 \mathrm{~ns}$ (FWHM) pulsed high voltage, which is loaded to the eight accelerating cavities. The 2 MV pulsed high voltage is loaded on an anodecathode (A-K) gap through superposition by a cathode rod and an anode rod. The A-K gap is adjustable from 80 to $130 \mathrm{~mm}$. Six standard turbomolecular pumps, mounted on the wall of vacuum chamber, provide an effective pumping 


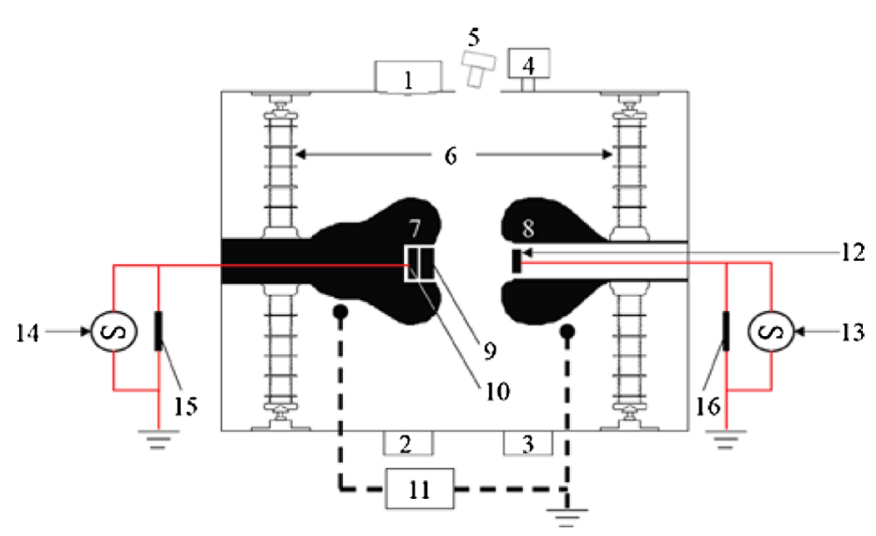

FIG. 1. Schematic diagram of experimental setup of the $2 \mathrm{MeV}$ LIA injector. 1, 2, 3: turbomolecular pumps; 4: quadrupole mass spectrometer and IVG; 5: CCD camera; 6: insulator; 7: cathode; 8: anode; 9: bakeout device and CNT cathode; 10: sampling resistor; 11: pulse power system; 12: Faraday cup; 13, 14: oscillograph; 15, 16: resistance.

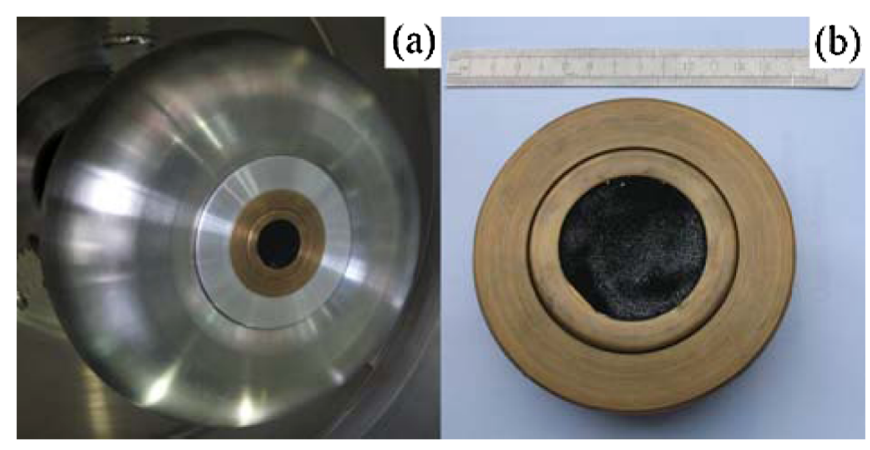

FIG. 2. Cathode of the $2 \mathrm{MeV}$ LIA injector diode: (a) cathode, (b) CNT cathode and bronze subassembly.

speed of $3760 \mathrm{~L} / \mathrm{s}$ for the vacuum chamber with a volume of about $1550 \mathrm{~L}$. Pressure and the outgassing are measured using an ionization vacuum gauge (IVG). During experiments, the base pressure is maintained within the range of $1.7 \times 10^{-4}-7 \times 10^{-4} \mathrm{~Pa}$. The charge coupled device (CCD) camera is used to observe the luminescence of the cathode plasma. The cathode current $I_{k}$ is measured by a sampling resistor inside cathode, and the anode current $I_{a}$ is collected by a Faraday cup in the anode hole. Multiwalled CNTs, synthesized by the thermal chemical vapor deposited process [22], are used as the field emission cathode. The cathode of the $2 \mathrm{MeV}$ LIA injector diode and CNT cathode are shown in Fig. 2. We conduct all tests at an $11.0 \mathrm{~cm}$ A-K gap, under the $1.7 \mathrm{MV}$ pulsed high voltage for stable operation.

\section{EXPERIMENTAL RESULTS AND DISCUSSIONS}

\section{A. Intense electron emission and diode perveance}

Figure 3(a) is the image of the background of the CNT cathode and Figs. 3(b)-3(d), 3(f), and 3(g) show the CCD images of PFE of the CNT cathode under diode voltages of 1.33-1.64 MV. The CCD images show the spatial distribution of plasma light on the cathode surface. As shown in Fig. 3, the luminescent zones in the images are the electron emission sites. There are many separate emission sites on the cathode surface. The intensity and distribution of cathode plasma are not uniform under lower diode voltage, but become uniform as the diode voltage increases. The emission intensity and the distribution determine the emission current. As the cathode plasma is expanding, the cathode plasma shell covers almost the whole CNT cathode surface, which is observed when cathode emission current reached $2.3 \mathrm{kA}$. Some small bright spots in the CCD images are considered as the random noise caused by the electromagnetic field due to the pulsed electron beams movement. The CCD images show that the cathode plasma is formed on the CNT cathode surface, and space-chargelimited flow is extracted from the cathode plasma.

Figure 4 gives the typical waveforms of the diode voltages and the emission currents from the CNT cathode in six shot experiments. Figure 4(a) presents diode voltages within the range of 1.33-1.64 MV. The anode currents and cathode currents are indicated by the data in Figs. 4(b) and 4(c), respectively. The highest pulsed high voltage is about 1.64 MV and the highest current reaches $2.31 \mathrm{kA}$ which means a current density of $127.8 \mathrm{~A} / \mathrm{cm}^{2}$. The cathode

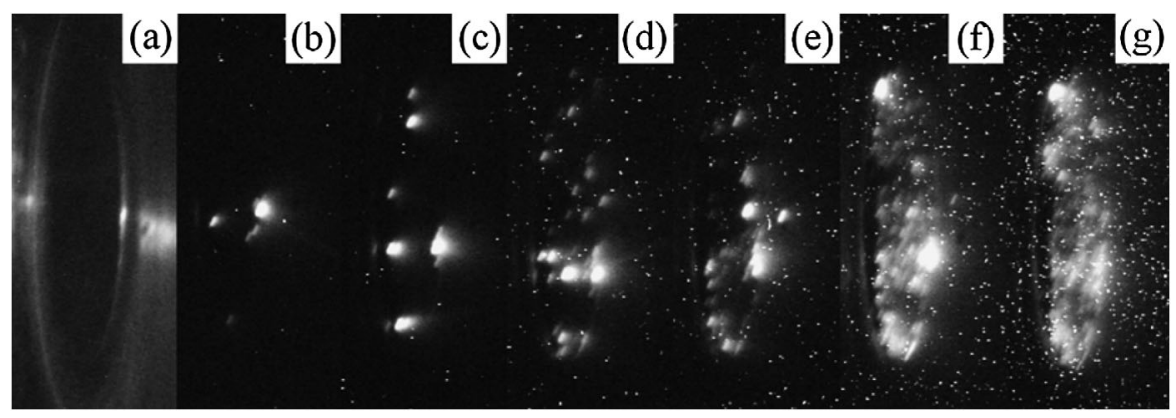

FIG. 3. CCD images: (a) background image of CNT cathode, (b)-(g) images of PFE of CNT cathode under diode voltages of 1.33$1.64 \mathrm{MV}$. 

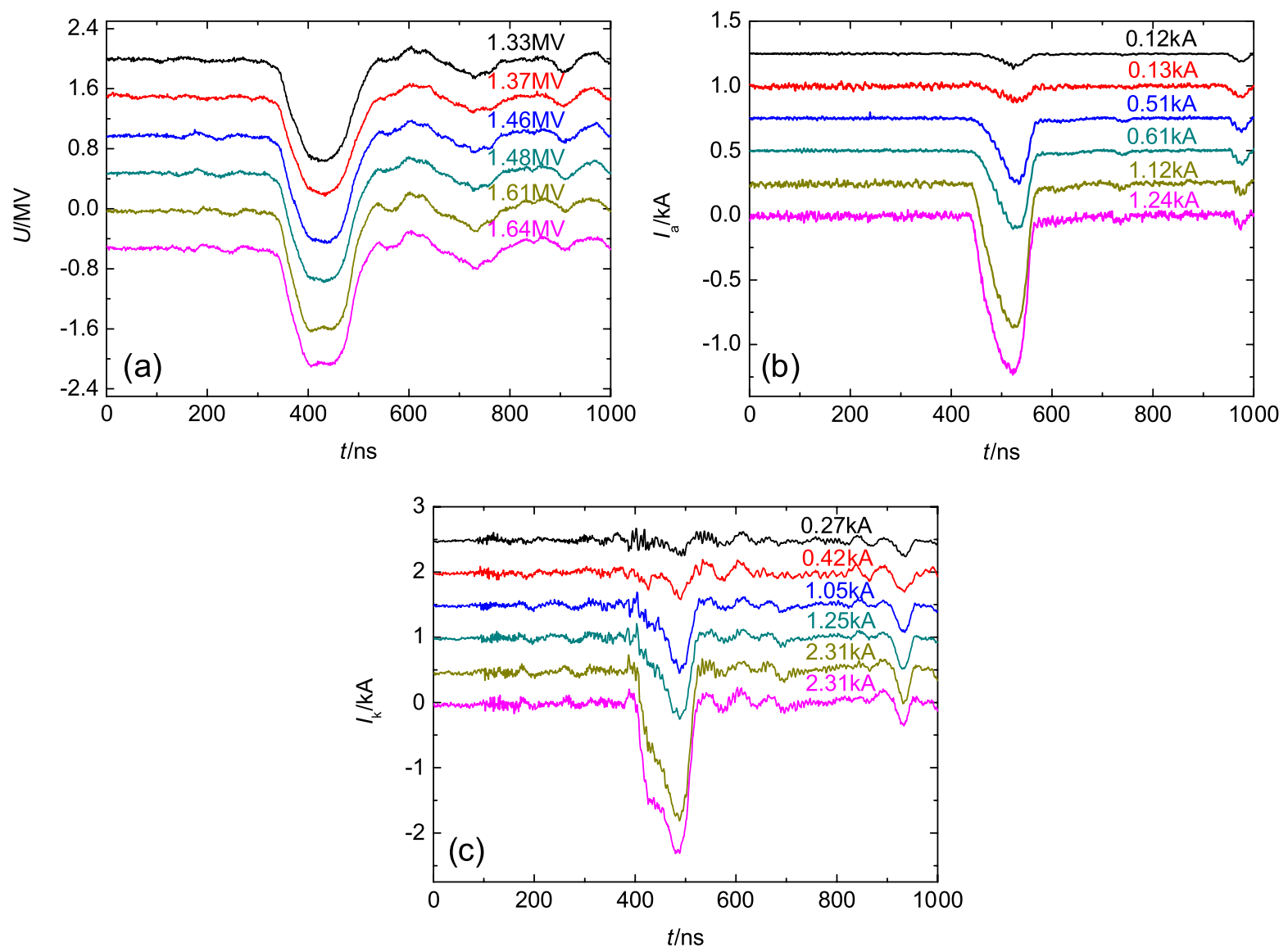

FIG. 4. Typical waveforms of the voltages and the currents: (a) diode voltages, (b) anode currents, and (c) cathode currents.

current is not equal to anode current as shown by the data in Table I. This indicates that a large amount of electron emission did not enter the anode hole, and so it was not collected by the Faraday cup. There are two main reasons which explain this. (1) With the absence of an external guiding magnetic field, the electron beam expands radially due to its own space charge. (2) The major factor is that the location of bronze subassembly used to fix the CNT cathode prevents focusing of the electron beam. There was no degradation in performance of the emission current after more than 300 shots under the same diode voltage. Table I summarizes the diode voltages, anode currents, cathode currents, and current densities under which the CNT cathode operates.

Figure 5 shows temporal variation of the voltage-current characteristic for the CNT cathode. The currents are presented here in the form of perveance $P_{d}=I / U^{3 / 2}$, where $I$ is the cathode current. The diode perveance grows significantly after the current initiation due to fast cathode plasma expansion under

$$
P_{d}=\frac{4}{9} \varepsilon_{0} \sqrt{\frac{2 e}{m_{e}}} \frac{\pi r^{2}}{\left(d-v_{p} t\right)^{2}},
$$

TABLE I. Results of six shot experiments of the CNT cathode: $U$ is diode voltage, $I_{a}$ is anode current, $I_{k}$ is cathode current, $j_{e}$ is current density, $P_{d}$ is diode perveance, $\Delta Q$ is the amount of outgassing, $\eta$ is ratio of outgassing and electron, and $\tau$ is CTT. The dots indicate that the data is not measured or calculated accurately.

\begin{tabular}{|c|c|c|c|c|c|c|c|c|}
\hline shot & $U(\mathrm{MV})$ & $I_{a}(\mathrm{kA})$ & $I_{k}(\mathrm{kA})$ & $j_{e}\left(\mathrm{~A} / \mathrm{cm}^{2}\right)$ & $P_{d}\left(10^{-6} \mathrm{I} / \mathrm{V}^{3 / 2}\right)$ & $\Delta Q(\mathrm{~Pa} \cdot \mathrm{L})$ & $\eta\left(\right.$ atoms $\left./ e^{-}\right)$ & $\tau(\mathrm{ns})$ \\
\hline $1 \mathrm{st}$ & 1.33 & 0.12 & 0.27 & 14.9 & 0.18 & 0.06 & $\ldots$ & $\ldots$ \\
\hline $2 \mathrm{nd}$ & 1.37 & 0.13 & 0.42 & 23.3 & 0.26 & 0.10 & $\ldots$ & $\ldots$ \\
\hline $3 \mathrm{rd}$ & 1.46 & 0.51 & 1.05 & 58.2 & 0.60 & 0.34 & 350 & 39 \\
\hline 4 th & 1.48 & 0.61 & 1.25 & 69.2 & 0.70 & 0.35 & 300 & 39 \\
\hline 5 th & 1.61 & 1.12 & 2.31 & 127.8 & 1.13 & 0.41 & 170 & 39 \\
\hline 6 th & 1.64 & 1.24 & 2.31 & 127.8 & 1.10 & 0.49 & 207 & 38 \\
\hline
\end{tabular}




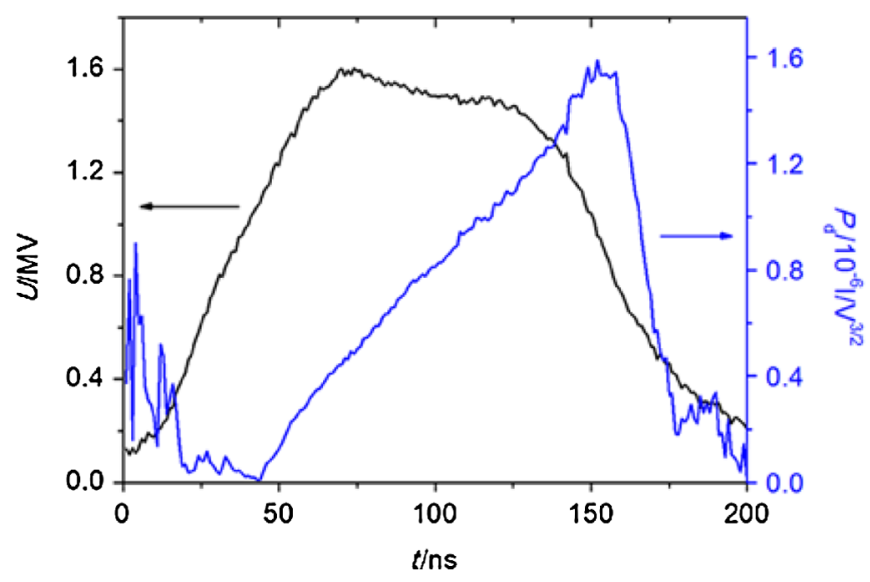

FIG. 5. Temporal variation of the voltage-current characteristics for the CNT cathode. Conditions: $U=1.61 \mathrm{MV}, I_{k}=$ $1.9 \mathrm{kA}$.

where $v_{p}$ is the plasma expansion velocity, $d$ is the effective emitter-anode gap, $r$ is the radius of electron source, $\varepsilon_{0}$ is the relative permittivity $\left(\varepsilon_{0}=8.85 \times 10^{-12} \mathrm{~F} / \mathrm{m}\right), e$ is the charge of electron $\left(e=1.6 \times 10^{-19} \mathrm{C}\right)$, and $m_{e}$ is the mass of electron $\left(m_{e}=9.1 \times 10^{-31} \mathrm{~kg}\right)$.

\section{B. Outgassing}

The IVG has been modified to monitor the vacuum chamber pressure. The analog output voltage signal of the IVG is directly observed by the oscillograph. There is a logarithm relationship between the output voltage $V(\mathrm{~V})$ and the vacuum pressure $p(\mathrm{~Pa})$ :

$$
V=6.25+0.326 \times \ln p
$$

In experiments, a pressure jump of the IVG is clearly observed after discharging. That is to say that the gases come from the CNT cathode and (or) anode materials with pulsed high voltage being loaded on the A-K gap for the single pulse mode, as shown in Fig. 6. In Ref. [23], 316 L $+\mathrm{N}$ stainless steel, oxygen-free high-conductance $\mathrm{Cu}$ and $\mathrm{Al}$ are reported to mainly desorb $\mathrm{H}_{2}$ due to electron induced gas desorption. In our case, the Faraday cup is made of tungsten. Based on the observer pressure rise, we deduce that tungsten mainly desorbs $\mathrm{H}_{2}$ due to charged particle bombardment. But in our study [24], the mass spectrum of the outgassing showed that most of the desorbed gas is $\mathrm{CO}_{2}$. Therefore, the gases come from the CNT cathode, rather than anode materials. Then, the amount of outgassing from the CNT cathode is calculated:

$$
\Delta Q=\int\left(p_{t}-p_{0}\right) \times S_{e} d t
$$

where $\Delta Q$ is the amount of the outgassing in units of $\mathrm{Pa} \cdot \mathrm{L} ; p_{0}$ is the base chamber pressure, $p_{t}$ is the chamber pressure changing in real time after diode discharging, the unit is $\mathrm{Pa}$; and $S_{e}$ is the effective pumping speed in units of $L / s$.
Figure 6 gives the waveforms of the pressure with the temporal variation in different diode voltages. Figures 6 and $6(\mathrm{~b})-6$ (f) correspond to Figs. 3(b) $-3(\mathrm{~g})$ and 1st-6th shots in Table I. The amount of outgassing is estimated to be $0.06-0.49 \mathrm{~Pa} \cdot \mathrm{L}$ by numerical integration of Eq. (3). At low pressures, the ideal gas law may be stated as $p V=$ $n R T$; thus, the number of atoms can be calculated:

$$
N_{a}=10^{-3} \frac{\Delta Q}{R T} N_{A}
$$

where $n$ is the amount of outgassing in mole; $R$ is the molar gas constant $(R=8.31 \mathrm{~J} /($ mole $\cdot \mathrm{K})) ; T$ is the room temperature $(T=300 \mathrm{~K})$; and $N_{A}$ is Avogadro's constant $\left(N_{A}=6.02 \times 10^{23} \mathrm{~mole}^{-1}\right)$. Also, the number of electrons could be estimated by numerical integration:

$$
N_{e}=\frac{\int I_{k} d t}{e}
$$

The highest outgassing reaches $0.49 \mathrm{~Pa} \cdot \mathrm{L}$ corresponding to $2.31 \mathrm{kA}$ cathode current. The ratio of outgassing and electron $\left(\eta=N_{a} / N_{e}\right)$ is roughly calculated to be 207 atoms per electron. This large outgassing per electron indicates that the cathode plasma is weakly ionized. For comparison in Table I, the ratios $\eta$ of the 3rd and 4th shots are seen to be larger than the 5th and 6th shots, because the PFE is the space-charge-limited flow process; the ability of extracting electron beams is weak due to the lower electric field of the $2 \mathrm{MeV}$ LIA injector diode. Larger outgassing could bring about higher cathode plasma density, but very few electrons could be extracted due to weaker extracting ability of the diode.

Furthermore, in order to study the effect of the outgassing during the PFE process, the effect of vacuum bakeout of the CNT cathode on the emission currents is investigated. A bakeout device is installed behind the CNT cathode, which heats the cathode by radiation. The temperature of the CNT cathode is about $450-550 \mathrm{~K}$ after bakeout. The CNT cathode desorbs gases with the temperature increasing. Thus, the electron beams are less intense due to decreasing gas density.

Figure 7 shows the effect on the emission current after vacuum bakeout of the CNT cathode; the cathode current and anode current are less than the emission current before vacuum bakeout. The results indicate that there has been obvious influence on the emission currents, and the emission currents have decreased 10\%-20\% after vacuum bakeout. As shown in Fig. 7(b), the cathode current does not rapidly increase with electric field increasing, as a result of desorbed gases that are pumped by the turbomolecular pump after vacuum bakeout. There are not enough gases for forming cathode plasma during the PFE process. Therefore, the experiments illustrate that the outgassing plays an important role in the formation of cathode plasma.

The OMS during intense electron emission of the CNT cathode was investigated by using the quadrupole mass 

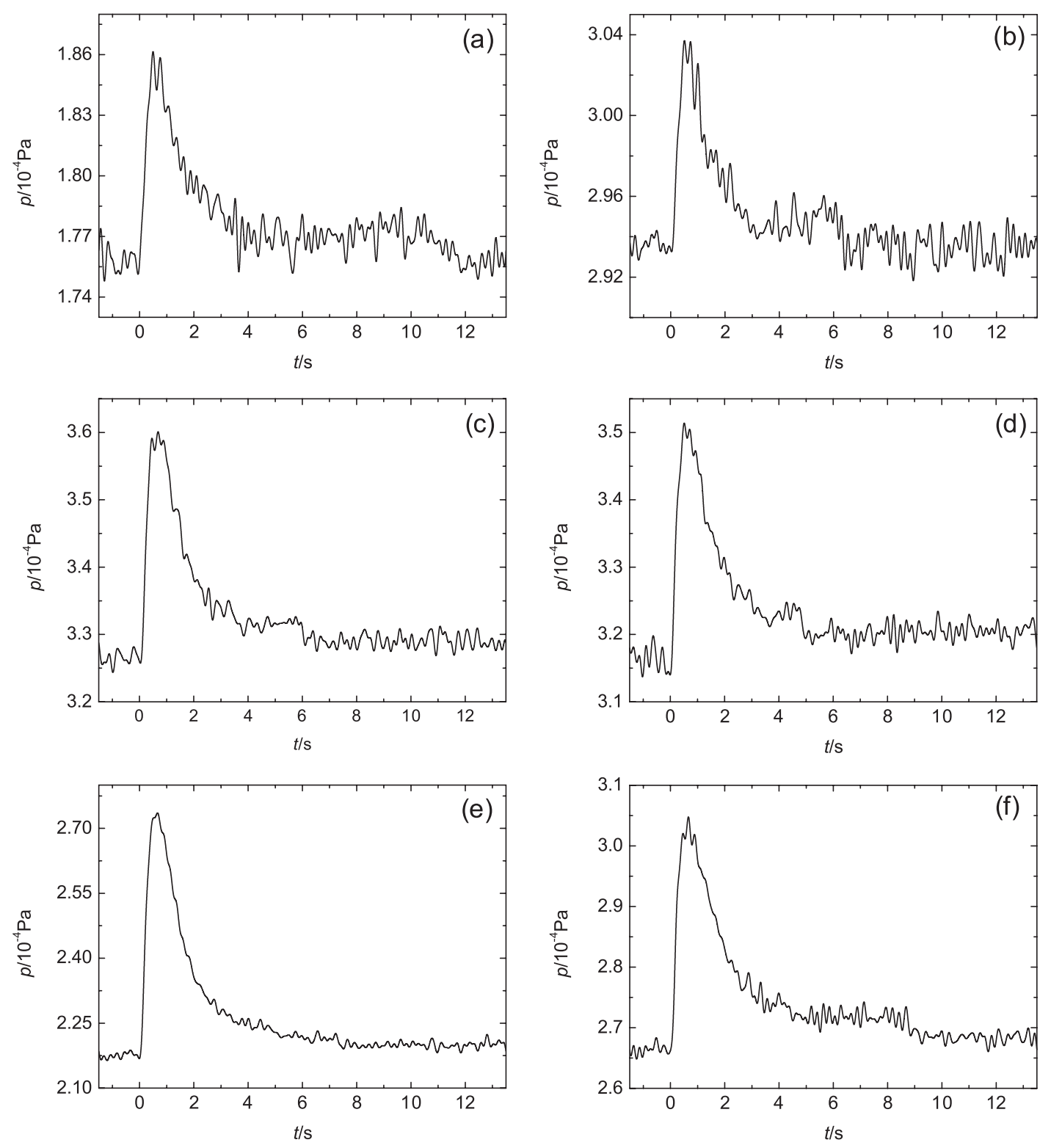

FIG. 6. Temporal variation pressure in different diode voltages: (a) $U=1.33 \mathrm{MV}$, (b) $U=1.37 \mathrm{MV}$, (c) $U=1.46 \mathrm{MV}$, (d) $U=1.48 \mathrm{MV}$, (e) $U=1.61 \mathrm{MV}$, and (f) $U=1.64 \mathrm{MV}$.
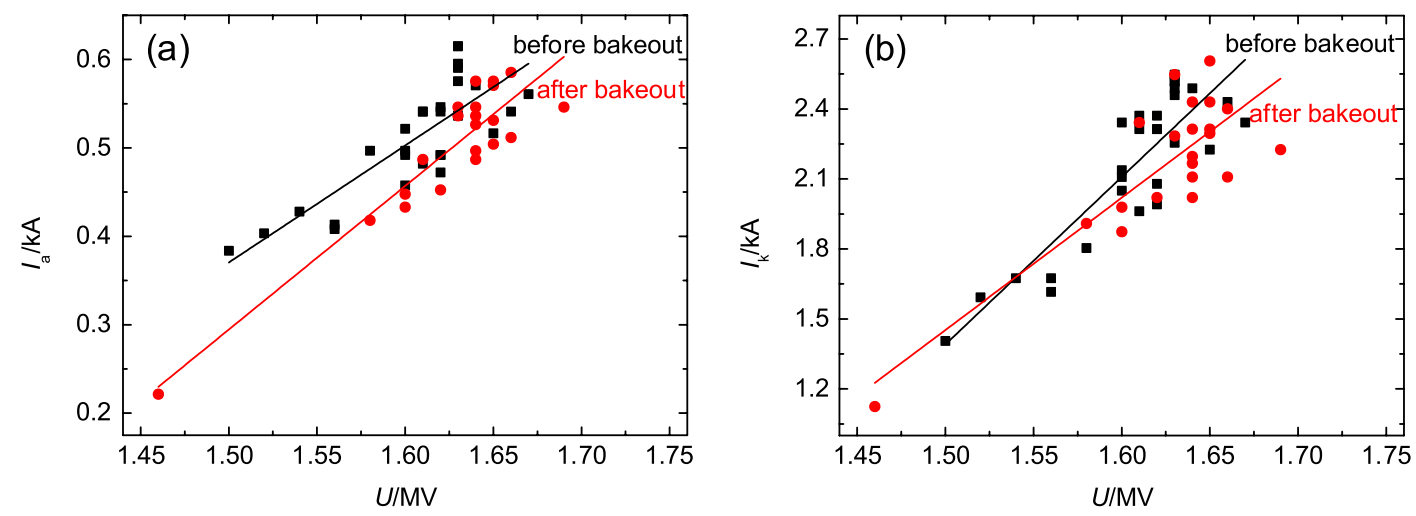

FIG. 7. Emission current before and after bakeout of the CNT cathode: (a) anode current, (b) cathode current. 

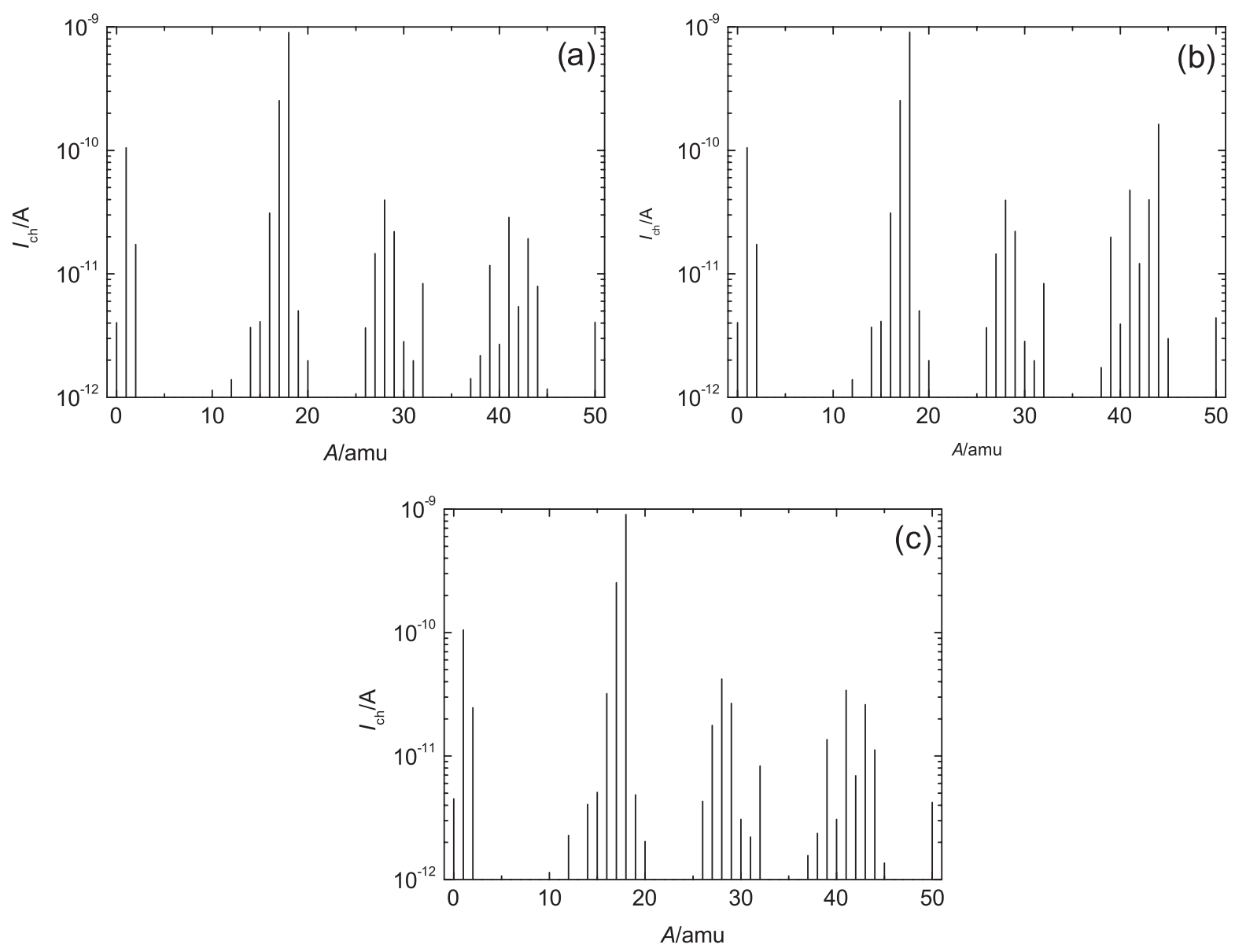

FIG. 8. OMSs of the CNT cathode: (a) before discharging, (b) on discharging, and (c) after discharging.

spectrometer. Figures 8(a)-8(c) show the OMSs before discharging, on discharging, and after discharging. Results show that most gases are $\mathrm{H}_{2} \mathrm{O}$ and a fragment of water $(\mathrm{HO})$ in the vacuum chamber. But the obvious characteristic current, $I_{\mathrm{ch}}$, of the $\mathrm{CO}_{2}, \mathrm{~N}_{2}(\mathrm{CO})$, and $\mathrm{H}_{2}$ are observed after discharging. Most of the desorbed gases

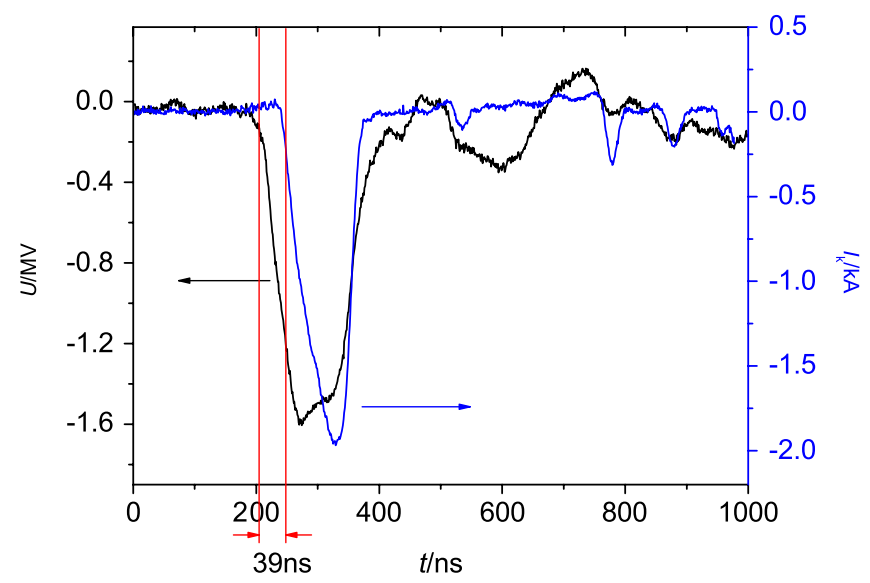

FIG. 9. CTT of the CNT cathode is $39 \mathrm{~ns}$. come from cathode materials. The desorbed gases of $\mathrm{CO}_{2}, \mathrm{~N}_{2}(\mathrm{CO})$, and $\mathrm{H}_{2}$ play an important role during the PFE process.

\section{Characteristic turn-on time}

A CTT $\tau$ needs to be reached before the electron emission is observed from the CNT cathode during the PFE process reported in this paper. The CTT has been easily measured by comparing the diode voltage and cathode current. The sampling resistor is installed near to the CNT cathode. The measurement error due to the displacement current is small compared to the cathode emission current. Thus, the amplitude of a $10 \%$ falling edge is regarded as the reference point (refer to the definition of the rise time), and the delay between the diode voltage and the cathode current could be considered as the CTT. In the experiments, the CTT of the CNT cathode is measured to be 39 ns, as shown in Fig. 9.

\section{CONCLUSIONS}

In this study, the PFE properties of the CNT cathode under pulsed electric field have been investigated for single 
pulse mode. The cathode is characterized as having intense electron beam emission and gas desorption. Intense electron beams of $14.9-127.8 \mathrm{~A} / \mathrm{cm}^{2}$ are obtained from the cathode at the pulsed electric field of $121-149 \mathrm{kV} / \mathrm{cm}$ and pulse duration of $\sim 100 \mathrm{~ns}$. The effect of the cathode plasma expansion on the diode perveance has been analyzed. The CNT cathode desorbs gases, and the amount of outgassing is estimated to be $0.06-0.49 \mathrm{~Pa} \cdot \mathrm{L}$ corresponding to a ratio of outgassing and electron emission of 350-170 atoms per electron. The effect of the outgassing during the PFE process has been observed at vacuum bakeout, and the mass spectrum of the outgassed material under intense pulsed emission of the CNT was studied. In conclusion, the outgassing plays an important role during the PFE process. Furthermore, the CTT of the CNT cathode is found to be $39 \mathrm{~ns}$. All these results demonstrate that the CNT cathode is able to emit intense electron current and is suitable for high power vacuum devices.

\section{ACKNOWLEDGMENTS}

This work is supported by the Foundation of State Key Laboratory for Advanced Metals and Materials of University of Science and Technology Beijing of China (Grant No. 20082D-10).

[1] R. B. Miller, J. Appl. Phys. 84, 3880 (1998).

[2] Y. M. Saveliev, W. Sibbett, and D. M. Parkes, J. Appl. Phys. 94, 7416 (2003).

[3] Ya. E. Krasik, A. Dunaevsky, A. Krokhaml, J. Felsteiner, A. V. Gunin, I. V. Pegel, and S. D. Korovin, J. Appl. Phys. 89, 2379 (2001).

[4] S. Iijima, Nature 56, 354 (1991).

[5] W. A. De Heer, A. Chatelain, and D. Ugarte, Science 270, 1179 (1995).

[6] C. Journet, W. K. Maser, P. Bernier, A. Losiseau, M. Lamydela Chapelle, S. Lefrant, P. Deniard, R. Lee, and J. E. Fischer, Nature (London) 388, 756 (1997).
[7] Y. Wei, C. Xie, K. A. Dean, and B.F. Coll, Appl. Phys. Lett. 79, 4527 (2001).

[8] J. T. L. Thong, C. H. Oon, W. K. Eng, W. D. Zhang, and L. M. Gan, Appl. Phys. Lett. 79, 2811 (2001).

[9] M. Endo, T. Hayashi, Y. A. Kim, M. Terrones, and M.S. Dresselhaus, Phil. Trans. R. Soc. A 362, 2223 (2004).

[10] Y. Saito, K. Hamaguchi, R. Mizushima, S. Uemura, T. Nagasako, J. Yotani, and T. Shimojo, Appl. Surf. Sci. 146, 305 (1999).

[11] Q. H. Wang, A. A. Setlur, J. M. Lauerhaas, J. Y. Dai, E. W. Seelig, and R.P.H. Chang, Appl. Phys. Lett. 72, 2912 (1998).

[12] G.Z. Yue, Q. Qiu, B. Gao, Y. Cheng, J. Zhang, H. Shimoda, S. Chang, J. P. Lu, and O. Zhou, Appl. Phys. Lett. 81, 355 (2002).

[13] Z. Liu, G. Yang, Y.Z. Lee, D. Bordelon, J. Lu, and O Zhou, Appl. Phys. Lett. 89, 103111 (2006).

[14] H. Schmid and H. W. Fink, Appl. Phys. Lett. 70, 2679 (1997).

[15] Q. Liao, Y. Zhang, J. Qi, Y. Huang, L. Xia, Z. Gao, and Y. Gu, J. Phys. D 40, 3456 (2007).

[16] Q. Liao, Y. Yang, J. Qi, Y. Zhang, Y. Huang, L. Xia, and L. Liu, Appl. Phys. Lett. 96, 073109 (2010).

[17] Q. Liao, Y. Zhang, Y. Huang, J. Qi, Z. Gao, L. Xia, and H. Zhang, Appl. Phys. Lett. 90, 151504 (2007).

[18] M.E. Read, W. G. Schwarz, M. J. Kremer, J. D. Lennhoff, D. L. Carnahan, K. Kempa, and Z. F. Ren, in Proceedings of the Particle Accelerator Conference, Chicago, IL, 2001 (IEEE, New York, 2001), p. 1026.

[19] D. Shiffler, O. Zhou, C. Bower, M. LaCour, and K. Golby, IEEE Trans. Plasma Sci. 32, 2152 (2004).

[20] Y. Shen, L. Xia, Z. Huang, X. Liu, and Q. Liao, High Power Laser Part. Beams 23, 775 (2011).

[21] L. Xia, L. Zhang, Z. Huang, F. Gao, J. Shi, and J. Deng, High Power Laser Part. Beams 16, 943 (2004).

[22] Q. Liao, Y. Zhang, L. Xia, Y. Huang, J. Qi, Z. Gao, and H. Zhang, Acta Phys. Sin. 56, 5335 (2007).

[23] J. G. Goñi, AT-VA Technical Note No. 94-16, CERN, 1994.

[24] Y. Shen, H. Zhang, X. Liu, L. Xia, and A. Yang, Acta Phys. Sin. 60, 080702 (2011). 